\title{
Adjusting External Doses from the ORNL and Y-12 Facilities for the Oak Ridge Nuclear Facilities Mortality Study
}

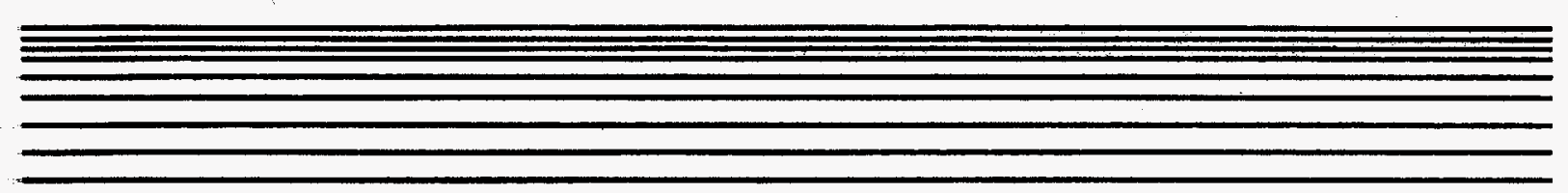

J.P. Watkins, D.L. Cragle, E.L. Frome, C.M. West, D.J. Crawford-Brown, and W.G. Tankersley 


\section{DISCLAIMER}

This report was prepared as an account of work sponsored by an agency of the United States Government. Neither the United States Government nor any agency thereof, nor any of their employees, make any warranty, express or implied, or assumes any legal liability or responsibility for the accuracy, completeness, or usefulness of any information, apparatus, product, or process disclosed, or represents that its use would not infringe privately owned rights. Reference herein to any specific commercial product, process, or service by trade name, trademark, manufacturer, or otherwise does not necessarily constitute or imply its endorsement, recommendation, or favoring by the United States Government or any agency thereof. The views and opinions of authors expressed herein do not necessarily state or reflect those of the United States Government or any agency thereof. 


\section{DISCLAIMER}

Portions of this document may be illegible in electronic image products. Images are produced from the best available original document. 


\title{
Adjusting External Doses from the ORNL and Y-12 Facilities for the Oak Ridge Nuclear Facilities Mortality Study
}

\author{
A Supplemental Report to \\ Data Collection, Validation, and Description for the \\ Oak Ridge Nuclear Facilities Mortality Study
}

J. P. Watkins, ${ }^{1}$ D. L. Cragle, ${ }^{1}$ E. L. Frome,${ }^{2}$ C. M. West ${ }^{1}$

D. J. Crawford-Brown, ${ }^{3}$ and W. G. Tankersley ${ }^{1}$

${ }^{1}$ Oak Ridge Institute for Science and Education, Medical Sciences Division, Center for Epidemiologic Research, Oak Ridge, TN 37831-0117.

${ }^{2}$ Oak Ridge National Laboratory, Oak Ridge, TN 37830.

${ }^{3}$ School of Public Health, University of North Carolina, Chapel Hill, NC 27599-7400.

This report concerns work undertaken as part of the Health and Mortality Study o Department of Energy workers being conducted by Oak Ride Associated Universities with the collaboration of the School of Public Health, University of North Carolina at Chapel Hill under Contract No. DE-AC05-76OR00033 between the Department of Energy, Office of Energy Research, and Oak Ridge Associated Universities. 


\section{TABLE OF CONTENTS}

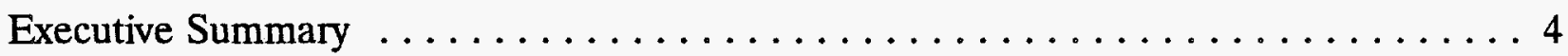

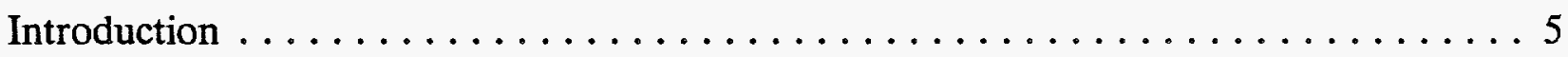

Adjustments to ORNL External Doses $\ldots \ldots \ldots \ldots \ldots \ldots \ldots \ldots \ldots$

Background $\ldots \ldots \ldots \ldots \ldots \ldots \ldots \ldots \ldots \ldots \ldots \ldots \ldots \ldots \ldots \ldots \ldots \ldots$

Selection of Unexposed Employment-Years $\ldots \ldots \ldots \ldots \ldots \ldots \ldots \ldots$

Hardcopy Monitoring Records $\ldots \ldots \ldots \ldots \ldots \ldots \ldots \ldots \ldots$

Use of Pocket Meter Data for Adjustment of 1944-1956 Doses . . . . . . . 12

Replacement of 1943 Unmonitored Employment-Years . . . . . . . . . 16

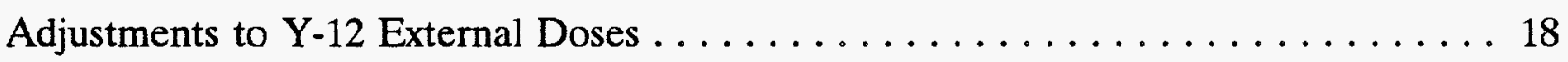

Background $\ldots \ldots \ldots \ldots \ldots \ldots \ldots \ldots \ldots \ldots \ldots \ldots \ldots \ldots \ldots \ldots \ldots \ldots \ldots$

Estimating Doses for Unmonitored Employment-Years, 1947-60 . . . . . . 18

Dose Adjustments for 1948 and $1949 \ldots \ldots \ldots \ldots \ldots \ldots \ldots \ldots \ldots$

Replacement of Missing Doses by the Nearby Procedure $\ldots \ldots \ldots \ldots \ldots \ldots 22$

Results of Dose Adjustment on Cumulative Doses $\ldots \ldots \ldots \ldots \ldots \ldots \ldots \ldots$

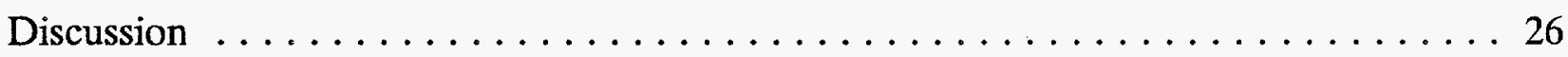

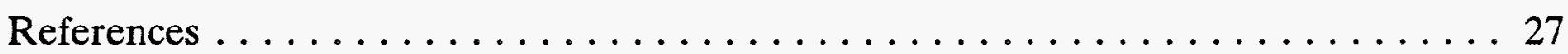




\section{LIST OF TABLES AND FIGURES}

\section{Tables}

Table 1

Definition of Abbreviations Used in Hardcopy Record $\ldots \ldots \ldots \ldots \ldots \ldots \ldots$

Table 2

Number of Annual Recorded External Doses

and Unmonitored Years Adjusted for ORNL . . . . . . . . . . . . 17

Table 3

Number of Annual Recorded External Doses

and Unmonitored Years Adjusted for Y-12 . . . . . . . . . . . . . 21

\section{Figures}

Figure 1

Sample Hardcopy External Exposure Record from ORNL $\ldots \ldots \ldots \ldots \ldots \ldots$

Figure 2

Adjusting ORNL External Doses -1943 to $1956 \ldots \ldots \ldots \ldots \ldots \ldots \ldots$

Figure 3

ORNL Cumulative External Doses: $1943-1956 \ldots \ldots \ldots \ldots \ldots \ldots . \ldots \ldots$

Figure 4

Y-12 Cumulative External Doses: $1947-1960 \ldots \ldots \ldots \ldots \ldots \ldots \ldots$ 


\section{EXECUTIVE SUMMARY}

An earlier report, Data Collection, Validation, and Description for the Oak Ridge Nuclear Facilities Mortality Study (Watkins et al., 1993), described demographic and radiation exposure data characteristics, and the effect of monitoring policies and practices on annual recorded external radiation doses and internal radiation exposure indicators for workers employed in nuclear facilities in Oak Ridge, Tennessee, through 1984. Investigations of changing monitoring policies and practices from the Oak Ridge National Laboratory (ORNL) and the Y-12 site indicated that certain annual recorded doses were likely to be biased downward. To evaluate the effect of this bias on dose-response coefficients, the report concluded that adjusted annual external doses should be calculated as replacements.

As a supplement to the earlier report, this report details specific procedures used for adjusting doses from ORNL and the Y-12. Comparisons of unadjusted and adjusted cumulative external doses for both facilities are also presented. For ORNL, the only major change in dose distribution was percent of workers with a cumulative dose of zero through 1956; this percent decreased from $31.9 \%$ to $11.7 \%$. The mean cumulative dose increased from 1.08 to $1.63 \mathrm{cSv}$, and the median increased from 0.13 to $0.46 \mathrm{cSv}$. For $\mathrm{Y}$ 12 , the decrease in percent of workers with a cumulative dose of zero was much more significant because few workers were monitored before 1961. As a result of the adjustment process, this percentage decreased from $74.3 \%$ to $10.1 \%$. However, most Y12 workers still had cumulative doses through 1960 of less than $1 \mathrm{cSv}$, with $50 \%$ having less than $0.2 \mathrm{cSv}$. The results of the dose-response analysis using unadjusted and adjusted doses will appear in a separate publication. 


\section{INTRODUCTION}

A previous ORISE technical report (Watkins et al., 1993), to which this report is a supplement, described how doses were obtained for the Oak Ridge nuclear facilities mortality study (Frome et al., 1994). The annual recorded external dose was the sum of film badge readings for the year, and any unmonitored year was considered to have a zero occupational dose. The magnitude of a recorded dose reflected not only the amount of occupational radiation exposure, but also monitoring and recording policies and practices at the time. These policies and practices are discussed and summarized in Watkins et al. (1993). (See "Monitoring Policies at the Facilities" and "Monitoring Data Characteristics of the Study Cohort," and Figures 3, 4, 6, B1, and B2.)

As a result of investigating monitoring and recording policies in effect at each facility over the 42 year study period, it was determined that, despite different approaches in facility monitoring programs, certain annual recorded doses likely underestimated actual doses from both ORNL and Y-12. Therefore, for the doseresponse analysis subcohort (white male employees of ORNL or Y-12), upward adjustments were made to appropriate annual recorded external doses for ORNL

employment-years prior to 1957 , and estimated doses were derived to replace Y-12 unmonitored employment-years prior to 1961. For both facilities doses were also estimated for the small percentage of annual doses that were missing during years when policy required monitoring all workers. 


\section{ADJUSTMENTS TO ORNL EXTERNAL DOSES}

\section{Background}

From mid-1944 through mid-1956, film badges for ORNL workers were read weekly, allowing only a short time to accumulate exposure. It was general practice to record as zero those readings below the detection limit of the badge. From 1948 through 1951 the detection limit was taken to be $0.03 \mathrm{cSv}$. During other periods it was dependent on the sensitivity of specific batches of film, always being $0.05 \mathrm{cSv}$ or less and generally falling between 0.03 and $0.01 \mathrm{cSv}$ (Wing et al., 1994). The combination of weekly readings and the zero recording practice made it likely that annual recorded doses for many employment-years underestimated actual doses. For a worker in 1949 receiving $0.03 \mathrm{cSv}$ per week, random errors would result in badge readings below $0.03 \mathrm{cSv}$ approximately $50 \%$ of the time that typically would be recorded as zero. For remaining weeks the dose would be recorded as $0.03 \mathrm{cSv}$ or slightly higher. Based on these recording practices, nearly $50 \%$ of the actual dose may have been unrecorded for that year. Even workers in areas with higher exposure potential, whose weekly readings were generally greater than $0.03 \mathrm{cSv}$, could have weeks during the year when they received some dose but had recorded values of zero. After 1956 when film badges were read quarterly rather than weekly, the magnitude of missed dose was likely much smaller because film badges had 13 times as long to exceed the threshold value and record positive readings for employees who had small weekly exposures.

Readings of film badges placed at specific fixed locations throughout the $\mathrm{X}-10$ site support the premise that doses were underreported at ORNL prior to 1957 . These data indicate that exposure potential at the selected locations remained fairly constant for 
years just before and after the badge exchange frequency changed from weekly to quarterly, although the population average recorded dose increased significantly when quarterly readings were begun (Morgan, 1963; Morgan, 1968).

The problem of missing dose from annual recorded doses for ORNL workers has recently been examined by Kerr (1994). He recommends that doses for epidemiologic studies be reassessed using the vast amount of hardcopy data including personnel dose records, daily pocket meter readings, and monitoring results from building surveys and fixed stations. A significant expenditure of time and effort would be necessary to computerize these data before such a dose assessment could begin. Therefore, as a preliminary attempt to compensate for likely missed dose in annual recorded doses, the dose adjustment procedures described below have been implemented. A small sample of daily pocket meter readings were computerized for this purpose.

\section{Selection of Unexposed Employment-Years}

Not all members of the dose-response analysis subcohort at ORNL had employment-years that were candidates for upward dose adjustment. Certain classifications, (e.g., accountants), were likely to have no occupational radiation exposure associated with them. Therefore, it was necessary to separate employment-years that were likely to be unexposed work years from those with exposure potential. After identifying unexposed employment-years, a reasonable dose adjustment process could be applied to remaining annual recorded doses.

Less than $7 \%(2,096)$ of employment-years for the subcohort from 1944 through 1956 had missing annual recorded doses. Doses for these years were treated as zeros for 
adjustment purposes since they had been changed to zeros when calculating cumulative doses for dose-response analysis based on unadjusted doses. Another $45 \%(13,851)$ of 31,048 employment-years during this period had zero as the annual recorded dose. The following criteria were used to select the subgroup of zero doses that would not be adjusted:

- If all annual recorded doses for a worker employed five or more years were zero, then they remained zero; and

- If the department of employment for the majority of the working days in a given year (most prominent department) had $75 \%$ or more annual recorded doses of zero, then the dose remained zero.

Implementing these criteria resulted in approximately $20 \%$ of the zero doses for 1944 to 1956 remaining unadjusted. Remaining employment-years were adjusted upward by an algorithm developed after examining a sample of hardcopy records from ORNL. 


\section{Hardcopy Monitoring Records}

Hardcopy radiation exposure records were maintained for all employees. Included were all daily pocket ionization chamber (pocket meter) readings and weekly film badge dosimetry readings, along with relevant information related to interpretation or problems with data. The data were recorded in millirems $(\mathrm{mrem})$, where $1,000 \mathrm{mrem}=1 \mathrm{cSv}$. Copies of hardcopy dosimetry records for 211 employment-years from 1947 through 1955 obtained from ORNL were entered into a computer file so that the data would be available for the adjustment process. Eighteen other employment-years were rejected because the computerized annual recorded dose differed by $10 \%$ or more from the sum of the weekly film badge readings on the hardcopy record. Ninety of the 211 retained records were from a random sample of the population of all employment-years through 1955. The remaining 121 were selected randomly from specific dose ranges, since a random sample was likely to contain a large percentage of employment-years with a zero dose. Two-thirds of these 121 were obtained from four specific dose ranges up to $1.6 \mathrm{cSv}$ per year. The remainder represented five dose ranges with the lowest beginning at 1.5 cSv per year.

Figure 1 shows a hardcopy record in one of the formats used during these years, while Table 1 defines the abbreviations used in the record. 
Figure 1

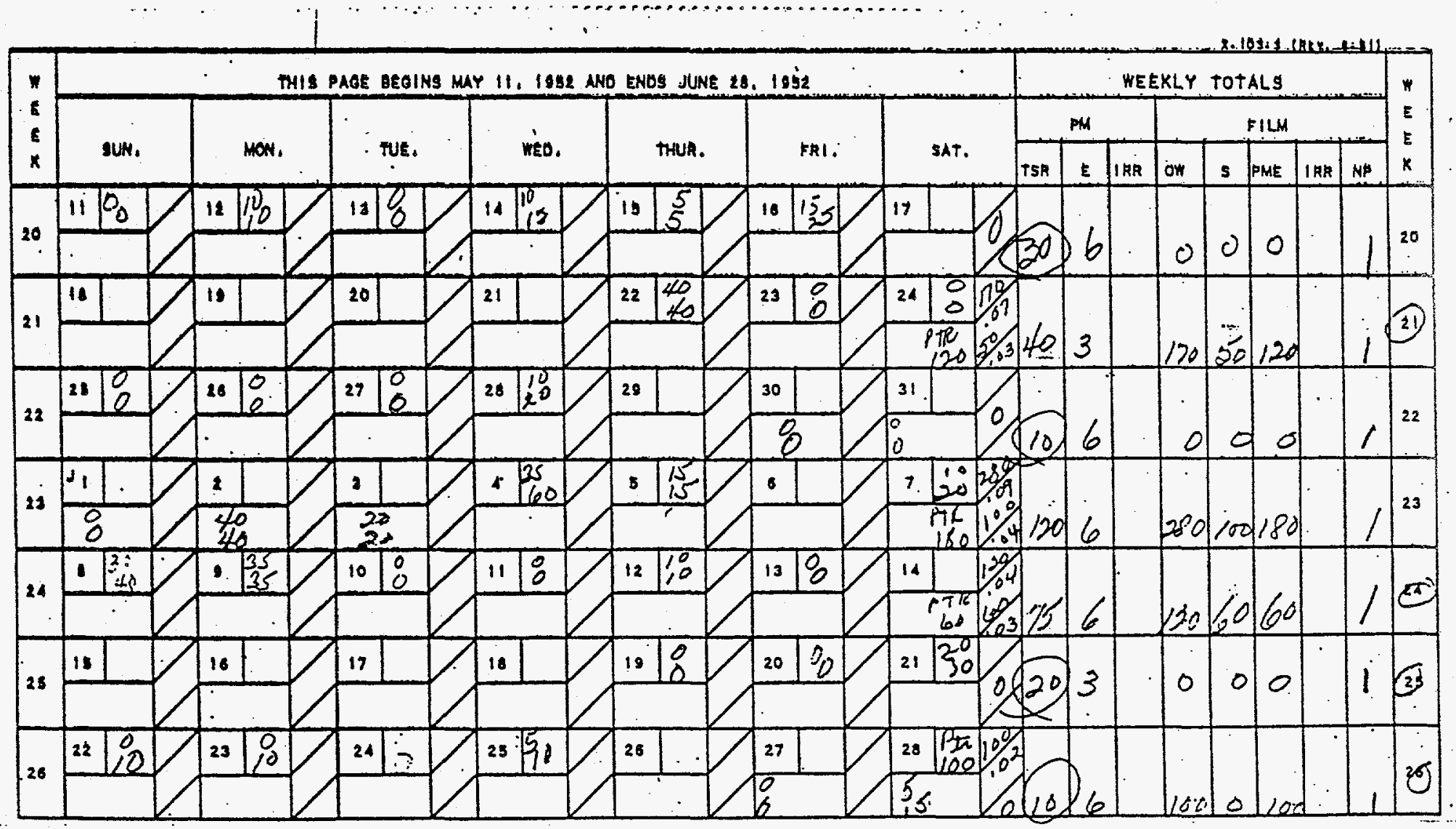


Table 1: Definitions of Abbreviations Used in Hardcopy Record

Weekly Totals Section

I. Pocket Meter (PM) Subsection

TSR - total significant reading

E - number of days with pocket meters

IRR - pocket meter irregularities

II. Film Badge (FILM) Subsection:

OW - open window reading

$\mathrm{S} \quad-\quad$ shielded reading

PME - $\quad$ probable maximum exposure for the film

IRR - film irregularities

NP - number of processes for film 
Pocket meters were assigned to workers in pairs because technical characteristics of these devices made them susceptible to discharging and registering a reading for reasons other than radiation exposure. The weekly pocket meter reading, reported as TSR, was then obtained by adding the minimum of each pair of daily readings. Not all of the hardcopy records had pocket meter readings or even film badge readings. Eleven of them were blank, and nearly all the others had weeks for which there were no film badge or pocket meter readings. These blank periods reflected an early ORNL policy to make monitoring available to everyone but only require monitoring devices to be worn by workers entering areas with exposure potential (Watkins et al., 1993). Other irregularities were noted, such as pocket meter readings off scale or film badges damaged in processing. Some records had weekly readings of 30 - (30 minus), indicating that the value was below the usual threshold of $30 \mathrm{mrem}(0.03 \mathrm{cSv})$. Such values had been taken as zeros in calculating annual recorded doses.

\section{Use of Pocket Meter Data for Adjustment of 1944-1956 Doses}

An annual film badge-pocket meter (FBPM) estimate of external dose from hardcopy records was obtained by summing weekly shielded film badge readings plus weekly pocket meter results, if available, for weeks with missing or zero shielded film badge readings. When weekly pocket meter readings were substituted for missing or zero film badge results, an upper limit of $0.06 \mathrm{cSv}$ was imposed on the substituted value. The rationale was that the film badge should have responded to an actual dose above that value. This limit was an additional safeguard against elevated pocket meter results not attributable to radiation exposure. 
An annual recorded dose of zero was associated with 55 of the 211 hardcopy record employment-years. Fifteen of these fifty-five annual doses were identified as unexposed employment-years using the selection criteria listed above in the section "Selection of Unexposed Employment-Years". Data from these 15 employment-years were not used in the dose adjustment process since they did not belong to the population to be adjusted. All fifteen of these employment-years had a FBPM dose of zero, confirming that the selection criteria were able to determine employment-years that were not associated with radiation exposure.

The FBPM doses contained dose estimates based on readings from both personal dosimeters, while annual recorded doses were based only on weekly film badge readings. The amount of dose missed by weekly readings and recording practices could be evaluated by subtraction. Therefore, the Estimate of Missed Dose (EMD) was calculated as the difference between FBPM dose and annual recorded dose.

Graphical inspection and smoothing techniques were used in selecting an appropriate method of incorporating pocket meter data into the adjustment procedure. Figure 2 shows the relationship between EMD and annual recorded dose for the 196 potentially exposed employment-years from the sample employment-years with hardcopy records. Although there is a cluster near zero, most annual recorded doses of zero had associated personal monitoring data indicating some external radiation dose during the year. In addition, most annual recorded doses above zero have monitoring data that demonstrate missing dose. A variable span smoother (Friedman, 1984) was applied to the data using the S-PLUS function, supersmu (Statistical Sciences, 1993) with the minimal smoothing option. The resulting fit appears in dashed lines. It revealed that a 
reasonable algorithm for adjusting annual recorded doses could contain two distinct parts - a quadratic curve up to approximately $1.6 \mathrm{cSv}$, followed by a horizontal line from 1.6 to $5 \mathrm{cSv}$.

A second degree polynomial was fit to doses below $1.6 \mathrm{cSv}$ in the sample using weighted least squares regression with EMD as the $y$-variate and annual recorded dose as the $\mathrm{x}$-variate. The weight for each observation was the ratio of number of days worked in the year to 365 . The regression yielded the following formula for the estimate of missed dose in the sample:

$$
\mathrm{EMD}=0.128+0.595 \mathrm{X}-0.306 \mathrm{X}^{2},
$$
where $\mathrm{X}$ is the unadjusted annual recorded dose in cSv.

The solid line shows this weighted least squares fit with the connecting horizontal line. To obtain adjusted annual doses this formula was applied to all employment-years with annual recorded doses less than $1.6 \mathrm{cSv}$ that were selected to remain zero. The placement of the horizontal line indicated that $0.3 \mathrm{cSv}$ should to be added to all annual recorded doses in the range of 1.6 to $5 \mathrm{cSv}$. For years of partial employment, the EMD was prorated to reflect the portion of the year worked. For approximately $5 \%$ of the doses, the number of days worked during that year was unknown, so no dose was added. 
Adjusting ORNL External Doses - 1943 to 1956
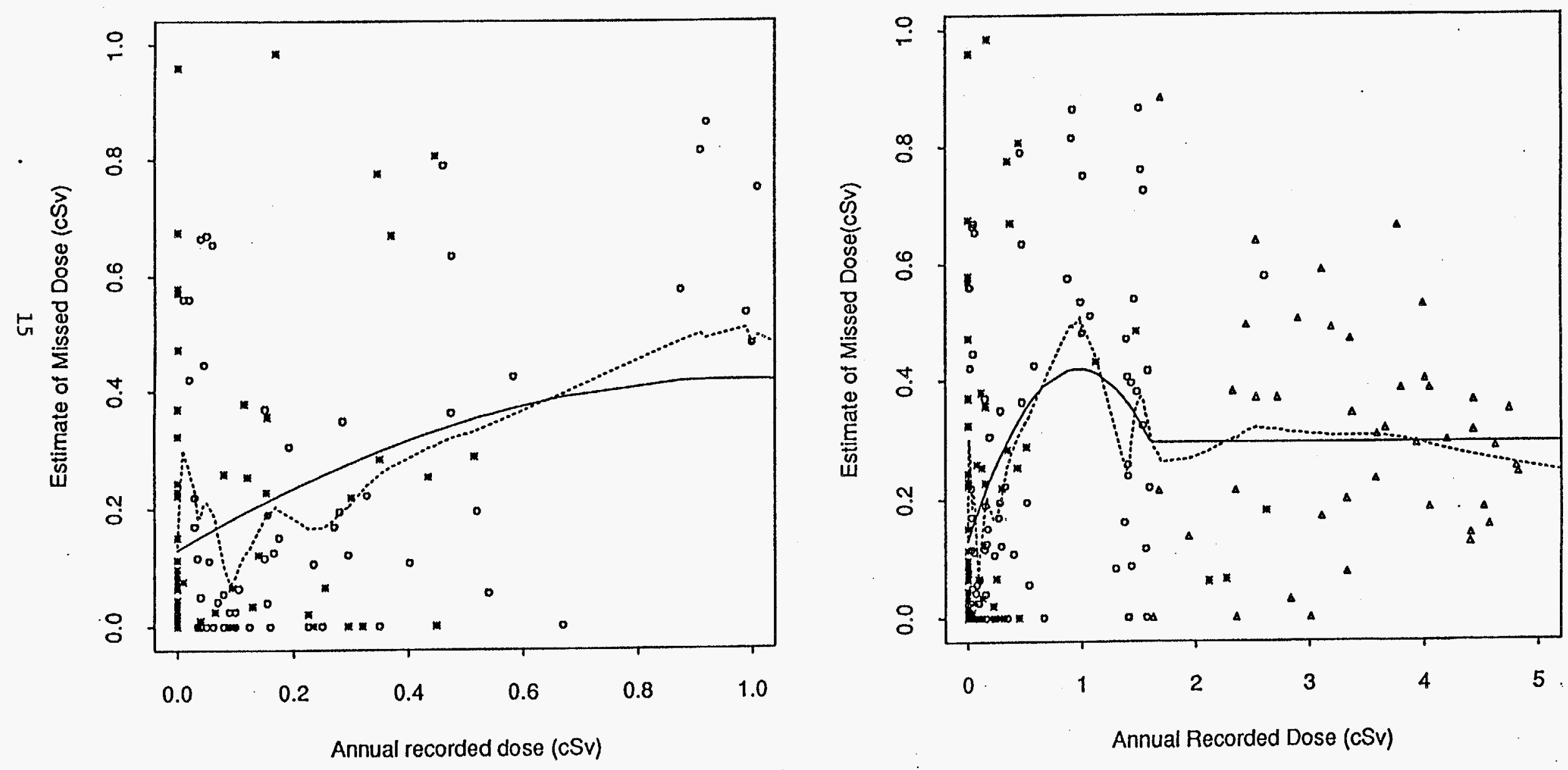

Estimate of yearly missed dose is sum of weekly pocket meter doses when weekly film badge doses $=0$ WLS Fit : Coefs $=0.128+0.595 *$ Dose $-0.306 *$ Square of Dose, for Doses $<1.6 \mathrm{cSV}$ 


\section{Replacement of 1943 Unmonitored Employment-Years}

The earliest assigned film badges at ORNL were for 1944. Annual recorded doses for 1943 were based entirely on pocket meter readings. Because 1943 doses had been derived in a different manner, they could not be included for adjustment with the doses from 1944 to 1956 . However, workers who were not monitored during 1943 were eligible to receive an estimated dose derived from the algorithm described below in the section entitled "Replacement of Missing Doses by the Nearby Procedure". In the case of the 1943 doses, no departmental medians were available because of sparse monitoring data during this first year of plant operation. Therefore, the departmental median section of the algorithm was not applied. All estimated doses were prorated to reflect the portion of the year employed.

Table 2 gives the distribution for ORNL of the numbers of annual doses that were adjusted or estimated and the methods by which they were obtained. 


\begin{tabular}{||c|c|}
\hline \multicolumn{2}{|c|}{$\begin{array}{c}\text { Table 2 } \\
\text { Number of Annual Recorded External Doses } \\
\text { and Unmonitored Years Adjusted for ORNL }\end{array}$} \\
\hline 1943 (682 possible annual doses) & 210 \\
\hline Nearby Procedure & 97 \\
\hline Plant median & 631 \\
\hline $1944-1956$ (31,048 possible annual doses) \\
\hline Set to zero by criterion $1^{\text {a }}$ & 5,976 \\
\hline Set to zero by criterion $2^{\mathrm{b}}$ & 23,149 \\
\hline Adjusted by formulac, & 1,147 \\
\hline Adjusted by constant value & \\
\hline 1957-1984 (114,499 possible annual doses) & 410 \\
\hline Nearby procedure & 96 \\
\hline Annual department medians & 73 \\
\hline Annual plant median & \\
\hline
\end{tabular}

${ }^{a}$ Employed for five or more years with all annual recorded doses of zero.

bDepartment of employment for majority of annual working days had $75 \%$ or more zero doses.

${ }^{c}$ Adjustment amount $=0.128+0.595 \mathrm{X}-0.306 \mathrm{X}^{2}$, where $\mathrm{X}$ is annual recorded dose in cSv.

d9,322 of the doses adjusted by the formula were former zero doses.

${ }^{\mathrm{e}} 0.3 \mathrm{cSv}$. 


\section{ADJUSTMENTS TO Y-12 EXTERNAL DOSES}

\section{Background}

Emphasis at $\mathrm{Y}-12$ was placed on monitoring internal radiation exposure because of the nature of production processes performed at this facility (Watkins et al., 1993). Before 1961 the policy at Y-12 was to issue film badges only to those employees who, based on their exposure potential, could exceed $10 \%$ of the occupational external radiation protection standard, which was $15 \mathrm{cSv}$ per year at that time. This practice resulted in 80 to $95 \%$ (depending upon the year) of employment-years being unmonitored for external dose prior to 1961. Because workers monitored with film badges at Y-12 before 1961 were selected according to their potential to receive at least moderate external doses, $7,358(14 \%)$ annual recorded doses that were based on these film badge readings were not adjusted. It was reasoned that for these workers the annual recorded dose would be the best estimate of dose available, particularly since workers with higher exposure potential would be less likely to have film badge readings below the dosimeter threshold. An exception to this was the revision of 104 doses from 1948 and 1949 , which were based on a very few film badge readings during the years when the external monitoring program was just beginning at $\mathrm{Y}-12$. The revision of these doses is discussed in the section entitled "Dose Adjustment for 1948 and 1949." Estimating Doses for Unmonitored Employment-Years, 1947-1960

An algorithm was developed to estimate doses for unmonitored employment-years during this time period. It was applied to Y-12 members of the subcohort used in doseresponse analysis. This algorithm was based on work history information for the subcohort, and it derived doses for unmonitored employment-years from logically related 
monitoring data in an immediately following time period. Because some workers likely received no occupational exposure, specific employment-years were identified for which unmonitored values should be replaced by an estimated annual dose of zero. These employment-years were determined by the following criterion: If the most prominent department for the year had fewer than $10 \%$ monitoring during that year, then the dose estimate was zero. A zero dose estimate was applied to nearly $40 \%$ of unmonitored employment-years in this period. This percentage was judged to be credible because the nature of the work being conducted resulted in internally deposited uranium being the primary source of radiation exposure.

For approximately $8 \%$ of employment-years before 1961 , an unmonitored year had an actual recorded dose or doses within two years. In this situation the Nearby Procedure, as described in the section below, was implemented to obtain dose estimates. Remaining unmonitored employment-years were assigned doses of $0.045,0.070$ or $0.130 \mathrm{cSv}$, according to whether the most prominent department for the year was classified as having lower, moderate, or higher exposure potential, respectively. These values were selected as dose estimates based on recorded doses from the 1961 to 1965 period, when essentially all personnel were monitored. The 140 departments from 1961 to 1965 were ranked from lowest to highest potential exposure by departmental median doses and subdivided into three groups of approximately equal size. Medians of these three groups were taken as dose estimates for the 1947 to 1960 period. All dose estimates were prorated depending on the number of days worked during the year. 
Dose Adjustment for 1948 and 1949

During 1948 and 1949 at Y-12, pocket meters were more commonly used than film badges as dosimeters for monitoring external radiation exposure. Annual recorded doses were adjusted because many weeks had no recorded results and many others had assigned results of $30 \mathrm{mrem}(0.03 \mathrm{cSv})$, which was considered to be the minimum detectable limit for film badges at that time. Adjustments to dose estimates were made by first adjusting weekly results and then summing these to obtain the adjusted annual doses. Less than detectable, noncredible, or absent weekly results were replaced by 0.009 cSv., which was derived by probit analysis (Strom, 1983) and later verified to also be the weighted mean of a subset of representative pocket meter readings and another subset of credible film badge readings from 1948 and 1949.

All estimated doses were prorated to reflect the portion of the year employed. Table 3 shows the numbers of Y-12 annual doses that were adjusted or estimated and the methods by which they were obtained. 


\begin{tabular}{|c|c|}
\hline \multicolumn{2}{|c|}{$\begin{array}{c}\text { Table } 3 \\
\text { Number of Annual Recorded External Doses } \\
\text { and Unmonitored Years Adjusted for Y-12 }\end{array}$} \\
\hline \multicolumn{2}{|c|}{$1947-1960{\text { (51,854 possible annual doses })^{a}}^{a}$} \\
\hline Nearby & 4,242 \\
\hline Set to zero ${ }^{b}$ & 20,671 \\
\hline Higher exposure departments $^{c}$ & 5,677 \\
\hline Moderate exposure departments ${ }^{d}$ & 5,154 \\
\hline Low exposure departments ${ }^{\mathrm{e}}$ & 8,648 \\
\hline Revised (1948 and 1949) & 104 \\
\hline \multicolumn{2}{|c|}{$1961-1984$ (121,069 possible annual doses) } \\
\hline Nearby & 2,104 \\
\hline Annual department medians & $\overline{52}$ \\
\hline Annual plant median & 128 \\
\hline
\end{tabular}

a7,358 not adjusted because annual recorded doses were based on film badge records that had been selected for monitoring because of higher exposure potential.

${ }^{b}$ Most prominent department for the year had less than $10 \%$ monitored workers.

${ }^{c}$ Dose estimate was $0.130 \mathrm{cSv}$.

dDose estimate was $0.070 \mathrm{cSv}$.

'Dose estimate was $0.045 \mathrm{cSv}$. 
REPLACEMENT OF MISSING DOSES BY THE NEARBY PROCEDURE

After 1956 at ORNL and 1960 at Y-12, fewer than 3\% annual recorded doses were missing for all years combined. To replace these missing values with best estimates of doses, the Nearby Procedure was developed to obtain doses based on an individual's doses for up to two years on either side of the missing employment-year (Watson et al., 1994). This technique averaged available doses if they appeared both before and after the missing year or copied a dose when it appeared either only before or only after the missing year. When no doses were within two years of the missing value, the dose estimate was the median dose of all monitored workers in the most prominent department for the year, provided at least 25 monitored doses were available for calculating the median. When a departmental median could not be determined or the worker's department was not known, the plant median for the year was used.

\section{RESULTS OF DOSE ADJUSTMENT ON CUMULATTVE DOSES}

Because fewer than 3\% of ORNL doses after 1956 and Y-12 doses after 1960 were adjusted, the impact of the dose adjustment procedures on cumulative external doses used in dose-response analysis can be appraised by examining plots of cumulative dose distributions in earlier years. Figure 3 shows unadjusted and adjusted ORNL doses accumulated through 1956, while Figure 4 displays unadjusted and adjusted Y-12 cumulative doses through 1960. 
Figure 3 depicts a smooth, gradual shift toward higher values of cumulative dose resulting from the dose adjustment process. Except for the relatively large drop in the percentage of workers with a cumulative dose of zero through 1956 (from $31.9 \%$ to $11.7 \%$ ), no dramatic changes were observed. With dose adjustment, the cumulative dose mean increased from 1.08 to $1.63 \mathrm{cSv}$, and the median increased from 0.13 to $0.46 \mathrm{cSv}$.

The picture seen in Figure 4 is quite different. Because few Y-12 workers were monitored before 1961, the adjustment process resulted in a notable decrease in percentage of workers with a cumulative dose of zero (from $74.3 \%$ to $10.1 \%$ ). However, even after dose adjustment, most Y-12 workers still had cumulative doses through 1960 of less than $1 \mathrm{cSv}$, with $50 \%$ less than $0.2 \mathrm{cSv}$.

Comparing Figure 3 to Figure 4, it is apparent that, even after adjustment, ORNL workers had generally higher cumulative external doses than Y-12 workers over the first 14 years of each plant operation. This fact reflects the difference in work activities and materials present in the two plants. 
ORNL Cumulative External Doses: 1943 - 1956

For 7284 White Male Employees

Unadjusted Doses

\%Zero $=31.9$ Mean $=1.08 \mathrm{Med}=0.13$



4.5 Per Cent Greater Than 5 cSv
Adjusted Doses

$\%$ Zero $=11.7$ Mean $=1.63 \mathrm{Med}=0.46$

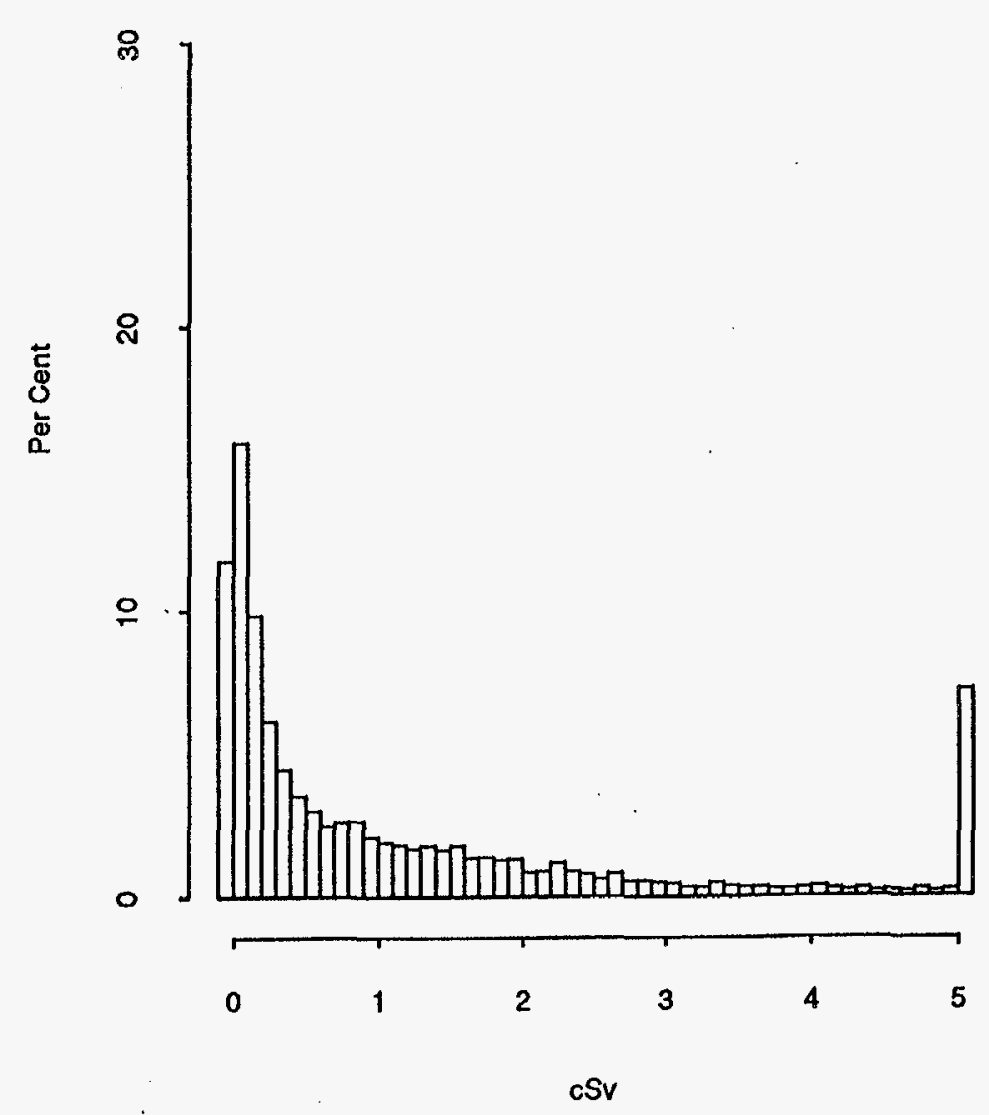

7.2 Per Cent Greater Than 5 cSv 
Figure 4

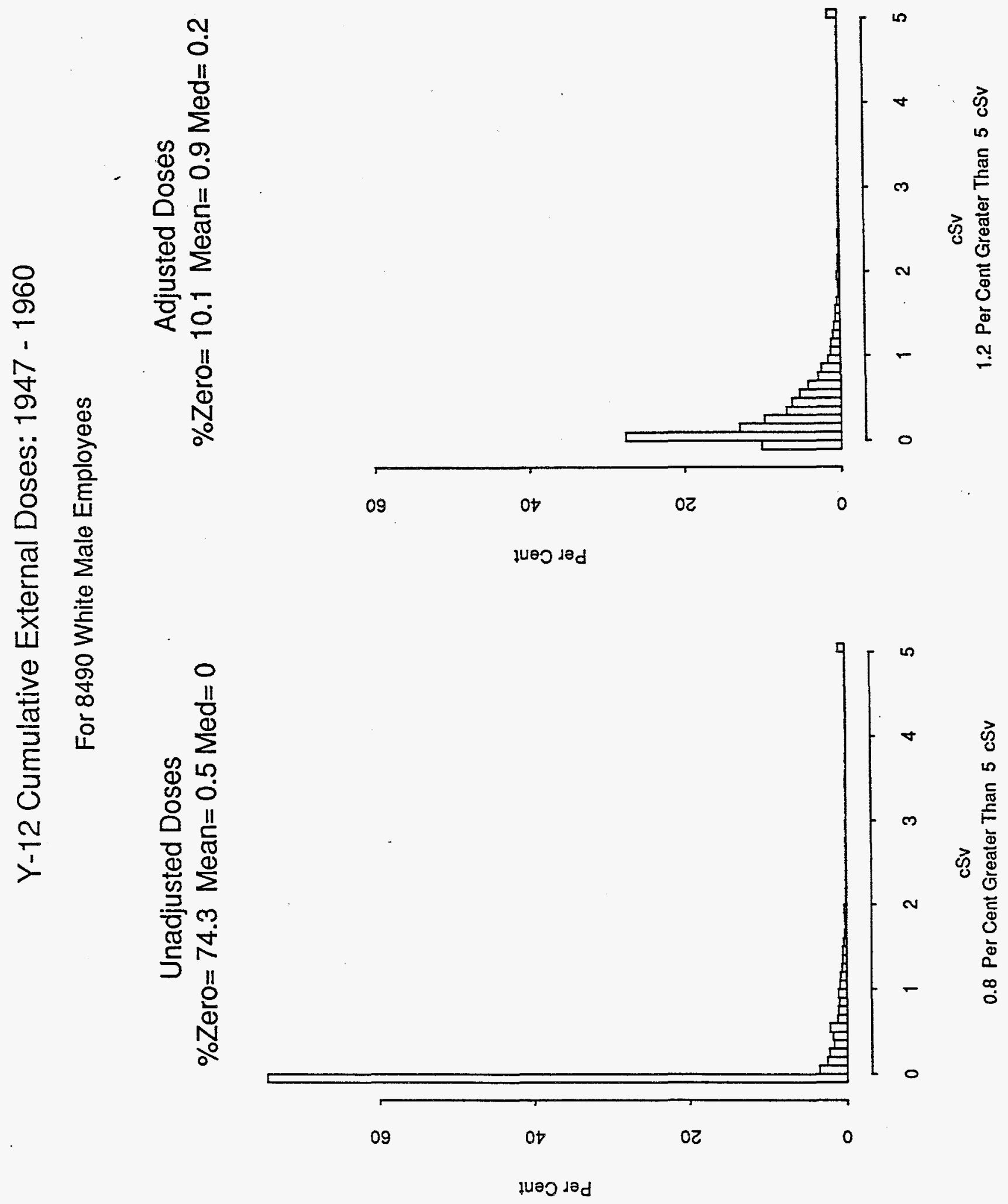




\section{DISCUSSION}

To evaluate the potential effect of missing dose on dose-response coefficients, a preliminary dose adjustment procedure was developed to assign adjusted doses to specific individual employment-years. This adjustment procedure made use of personal external monitoring data currently computerized; historical knowledge of evolving monitoring policies, practices, and dosimeters; knowledge of operations and production processes at these facilities; and a sample of pocket meter readings currently available only on ORNL hardcopy records. Limited data exist to further refine the Y-12 dose adjustment process. However, detailed hardcopy exposure records for approximately thirty thousand employment-years before 1957 at ORNL contain daily pocket meter and weekly film badge data that have not been computerized. More sophisticated and accurate adjustment techniques could be implemented for future studies if these personal monitoring data are computerized (Mitchell et al., 1993). 


\section{REFERENCES}

Friedman, J. H., A Variable Span Smoother. Technical Report No. 5, Laboratory for Computational Statistics, Department of Statistics, Stanford University, Stanford, CA, 1984

Frome, E. L., Cragle, D. L., Watkins, J. P., Wing, S., Shy, C., Tankersley, W. G., and West, C. M., A Mortality Study of Employees of the Nuclear Industry in Oak Ridge, Tennessee. In preparation, 1994

Kerr, G. D., Missing Dose from Mortality Studies of Radiation Effects among Workers at Oak Ridge National Laboratory. Health Physics, Vol. 66, No. 2, February 1994

Mitchell, T. J., Ostrouchov, G., Frome, E. L., and Kerr, G. D., A Method for Estimating Occupational Radiation Dose to Individuals, Using Weekly Dosimetry Data. Technical Report ORNL-6778, Oak Ridge National Laboratory, Oak Ridge, TN, December, 1993.

Morgan, K. Z., Snyder, W. S., and Davis, D. M., Applied Health Physics and Safety Annual Report for 1963. Technical Report ORNL-3665, Oak Ridge National Laboratory, Oak Ridge, TN, 1964

Morgan, K. Z., Davis, D. M., and Hart, J. C., Applied Health Physics and Safety Annual Report for 1968. Technical Report ORNL-4423, Oak Ridge National Laboratory, Oak Ridge, TN, 1969

Statistical Sciences, S-PLUS User's Manual, Version 3.0, Seattle: StatSci, a division of MathSoft, Inc., 1991

Strom, D. J., A strategy for Assessing Occupational Radiation Monitoring Data from Many Facilities for Use in Epidemiologic Studies. Doctoral Dissertation, University of North Carolina, Chapel Hill, N. C., 1983

Watkins, J. P., Reagan, J. L., Cragle, D. L., Frome, E. L., West, C. M., Crawford-Brown, D. J., and Tankersley, W. G., Data Collection, Validation, and Description for the Oak Ridge Nuclear Facilities Mortality Study. Technical Report ORISE 93/J-42, Oak Ridge Institute for Science and Education, Oak Ridge, TN, October, 1993

Watson, J. E., Wood, J. L., Tankersley, W. G., and West, C. M., Estimation of Radiation Doses from Workers without Monitoring Data for Retrospective Epidemiologic Studies. Health Physics, In Press.

Wing, S., West, C. M., Wood, J. L., and Tankersley, W. G.

Recording of external radiation exposures at Oak Ridge National Laboratory: implications for epidemiologic studies

JEAEE, 1994 